\title{
II. On the cause of the electricity of effluent steam
}

\section{Wm. George Armstrong Esq.}

To cite this article: Wm. George Armstrong Esq. (1842) II. On the cause of the electricity of effluent steam , Philosophical Magazine Series 3, 20:128, 5-8, DOI: $10.1080 / 14786444208650504$

To link to this article: http://dx.doi.org/10.1080/14786444208650504

$$
\text { 曲 Published online: } 01 \text { Jun } 2009 .
$$

Submit your article to this journal $\pi$
Џ Article views: 4 
plete dilution by water (see vol. xix. pp. 25 and 179). Hence $\mathrm{KO} . \mathrm{S} \mathrm{O}_{3}$ in combining with $\mathrm{SO}_{3}$ had disengaged the same quantity of heat as if the free acid had been fully diluted, and hence much more than an atom of water could. Hence $\mathrm{KO} . \mathrm{S} \mathrm{O}_{3}$ and $\mathrm{HO}$ are not thermometrically equivalent, as Graham's theory should require.

The total quantity of heat evolved by the formation of $\mathrm{K} \mathrm{O}+2 \mathrm{~S} \mathrm{O}_{3}$, M. Hess represents as made up of the following quantities :-

$\mathrm{K} \mathrm{O}$, evolves by combining with water........... $x$ units.

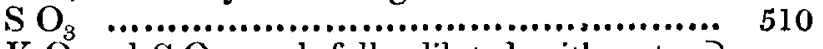

$\left.\begin{array}{l}\mathrm{KO} \text { and } \mathrm{S} \mathrm{O}_{3} \text {, each fully diluted with water, } \\ \text { evolve by combining with each other........ }\end{array}\right\} 407$

K O. $\mathrm{S} \mathrm{O}_{3}$ combining with $\left.\mathrm{S} \mathrm{O}_{3} \ldots \ldots \ldots \ldots . . . \quad 510\right\}$

If we place the numbers which represent the quantities of heat between the symbols of the bodies which evolve it, we have $\mathrm{KO} . x+917 \mathrm{SO}_{3} .510 \mathrm{~S} \mathrm{O}_{3}$.

To know with certainty the place of the water in the formula of the hydrated salt, we must estimate the quantity of heat evolved by its union, but it is so small that the exact determination is very difficult. If we term it. $y$. then the expression becomes $\mathrm{KO} \cdot \boldsymbol{x}+917 \mathrm{~S} \mathrm{O}_{3} \cdot 510 \mathrm{~S} \mathrm{O}_{3} \cdot y \mathrm{HO}$. The dry salt is therefore $\mathrm{KO}+2 \mathrm{SO}_{3}$, and the ordinary salt $\left(\mathrm{KO}+2 \mathrm{~S} \mathrm{O}_{3}\right)+\mathrm{HO}$.

M. Hess concludes with some observations on the necessity of a knowledge of the quantity of heat evolved by the combination of every essential element of a compound, to a correct knowledge of its theoretical nature, and suggests the determination of the relation between the quantities $x$ and 917 , and 510 and $y$ as an object of additional researches.

II. On the Cause of the Electricity of Effluent Steam. By Wu. George Armstrong, Esq.*

To the Editors of the Philosophical Magazine and Journal. Gentlemen,

A FTER an interval of several months, I have lately reA sumed my experiments on this curious subject, and have at length ascertained, that the place where the excitation of electricity is effected, is that at which the steam is subjected to friction.

In reflecting upon many of the experiments of which I have

[* On the subject of this paper see Phil. Mag., 3rd series, vol, xviii. pp. $93,95,100 .-$ EnIT. $]$ 
already published an account, I felt convinced that the electricity manifested in an insulated boiler, during the emission of steam, could not be attributed to the accompanying evaporation of the water; and being wholly unable to conceive any other cause, operating in the boiler, to which the effect could with any probability be ascribed, I became persuaded that the source of the electricity could only be situated at the discharging orifice, or in the channel through which the steam was conveyed to it. Such of my previous experiments as appeared to militate against this supposition, I conceived might probably have been rendered fallacious by the omission of proper precautions to prevent a conduction of electricity, by moisture, between parts of the apparatus which I had assumed to be insulated, with respect to each other. I therefore determined to repeat the principal experiment of this kind, with the addition of such measures as I deemed requisite, to obviate the defect I have alluded to, and the following is the mode in which I proceeded.

Into an insulated boiler I inserted one end of the glass tube $A$, which was placed in a horizontal position, and to the other extremity of which a stop-cock $\mathrm{C}$ was affixed, having a passage through it considerably smaller than that through the tube ; and in order to prevent any communication of electricity between the boiler and the cock by the deposition of moisture on the inner surface of the glass, I surrounded part of the tube with a red-hot iron cylinder, which is represented at B. I then attached to the cock a second glass tube D, from the extremity of which the steam was discharged.

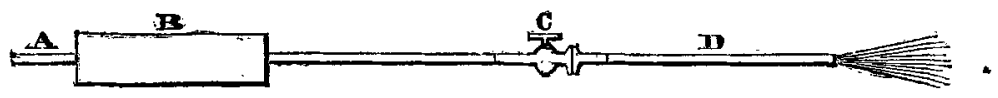

Upon opening the cock the ejected steam proved, as usual, to be positively electrified; but the boiler, which in all former experiments had yielded the opposite electricity to that of the steam-cloud, now remained neuter; and the cock, instead of the boiler, became negatively electrified. When I say that the boiler remained neuter, I must be understood to mean, that it was as nearly so as could be expected from the difficulty of wholly intercepting the transmission of electricity from the cock to the boiler. Feeble electricity did appear in the boiler, but no question could exist with respect to its origin; for when I touched the cock with a wire, the electricity of the boiler vanished entirely; but when I touched the boiler, the electricity of the cock was scarcely diminished; and upon forming a communication between the boiler and 
the cock, the boiler became negatively electrified in the usual degree.

It was obvious, therefore, that the excitation took place at the cock, where, by reason of the narrowness of the channel, the force of the current was chiefly exerted.

I then removed the second glass tube, and discharged the steam direct from the oock, which continued to be negatively electrified precisely the same as before.

The heat of the iron cylinder proved exceedingly apt to rupture the tube which passed through it, and several annoying explosions were in consequence occasioned during my experiments; but I afterwards found that sufficiently decisive results could be obtained, without the aid of external heat, merely by inclosing a portion of the tube, next to the boiler, in a cylindrical case, about three inches in diameter, stuffed with wool or other similar material.

I next made a number of experiments to ascertain the effect of varying the form and material of the aperture at which the electricity was excited; and, contrary to what I had expected, I found that apertures which were calculated to produce an increase of friction did not in general cause an increase of electricity, and very often had an opposite effect. Notwithstanding this, however, the intensity of the development proved to be greatly dependent upon the nature of the orifice employed; and to such a degree have I increased the electricity by modifying the orifice, that I have produced sparks four inches long, with an expenditure of steam not greater than would be occasioned by a circular aperture 1-10th of an inch in diameter. But my experiments on this head are, as yet, far from complete; and it would therefore be premature at present to describe them, or to hazard any opinion respecting the immediate cause of the electrical excitation.

I have also recently obtained some very remarkable results, relative to the transmutation which, under certain conditions, takes place in the electrical states of the steam-cloud and boiler. When the gun-metal boiler, or generator, which I have described in a former communication, was new, and its interior surface was rough and oxidized, as the surface of castings usually are, the electricity of the steam was uniformly positive, provided no corrosive material was mixed with the water; but lately, upon having the generator bored out, so as to give it a smooth metallic surface within, the steam became negatively electrified, although nothing was contained in the water to produce that effect. I afterwards had the inside of the generator coated with tin; but the steam still continued to be negatively electrified. 
8 Rev. P. Kelland on Mossotti's Theory of Molecular Aclion.

The boiler which I am now using is made of wrought iron, and the electricity of the steam discharged from it has been invariably positive, except in the instance $I$ am about to mention. Potash and soda, which in the gun-metal genarator tended so strongly to the increase of positive electricity in the steam-cloud, appear to have little influence when introduced in to the iron boiler; but I have not yet tried, in the iron boiler, the acids and other things which, in the gun-metal generator, caused the steam to give negative electricity.

In consequence, however, of the influence which the state of the inner surface of the generator had been proved to exert upon the electricity of the steam, I was induced to try whether the steam from the iron boiler could not be caused to evolve negative, instead of positive electricity, by being brought into contact with a considerable surface of polished brass on its way to the discharging aperture; and with this view, I conveyed the steam from the boiler through a brass tube, an inch and a half in diameter, made bright and smooth in the inside and terminating in a small hole, at which the steam was discharged. Under these circumstances the electricity of the steam continued to be positive, but was rendered exceedingly feeble. I then moistened the inside of the brass tube with dilute nitric acid, and, by this means, the steam from the iron boiler became for the first time negatively electrified, though not in a high degree.

Newcastle-upon-Tyne, Dec. 9, 1841 .

Wm. Geo. Ammstrong.

III. On Mossotti's Theory of Molecular Action. By the Rev. P. Kelland, M.A., F.R.SS. L.\& E., F.C.P.S., Professor of Mathematics in the University of Edinburgh, late Fellow and Tutor of, Queen's College, Cambridge.

\section{Dear Sir,}

To Richard Taylor, Esq.

T $T$ is with great pleasure that $I$ find attention at length di1 rected to the interesting subject of molecular equilibrium. Since the appearance of the translation of M. Mossotti's paper in the Scientific Memoirs*, nothing has been written relative to it, except my own memoir in the seventh volume of the Transactions of the Cambridge Philosophical Society. The duty of noticing any objections which are brought against the theory, may, therefore, seem to devolve on me. It is with this impression that I give the following explanation of the points

* Taylor's Scientific Memoirs, Vol. i. p. 448. 